\title{
Overall buckling behaviour of laminated CFRP tubes with off-axis ply orientation in axial compression
}

https://doi.org/10.1515/secm-2019-0007

Received July 22, 2018; accepted December 8, 2018

\begin{abstract}
This paper presents an experimental investigation of overall buckling behaviour of carbon fibre reinforced plastic (CFRP) tubes with different off-axis ply orientations. A series of specimens are designed and prepared with stacking sequences $\left[0^{\circ}{ }_{4} / \pm \theta^{\circ}\right]$, with $\theta$ corresponding to either $0,90,45$ or 60 . Axial compression tests with effective end-reinforcement and hinge support are performed to investigate the overall buckling behaviour. With respect to the future design and application of CFRP tubes with this type of stacking sequence, column curves for each stacking sequences and all test data are fitted based on Perry-Robertson formula. With respect to the high stress level in the relatively short CFRP tube that facilitates the development of defects, test data present high levels of discreetness. We propose a strategy for engineering safe design in which a reduction factor is added to the original reduction factor based on statistical analysis when the universal slenderness ratio is less than 2 .
\end{abstract}

Keywords: Overall buckling; CFRP tube; Column curve; off-axis ply orientation

\section{Introduction}

Fibre reinforced plastic (FRP) materials are attractive for engineering structures due to their excellent properties, related to high strength, light weight, and anti-corrosion behaviour [1, 2]. With the development of production technology, FRP materials exhibit promise in future engineering applications. Unidirectional pultruded FRP profiles (mainly GFRP profiles) are widely used in civil engineering structures such as truss bridges [3-6], space struc-

\footnotetext{
Ruijie Zhu, Dongdong Zhang: College of Field Engineering, Army Engineering University of PLA, Nanjing 210007, China *Corresponding Author: Feng Li: College of Field Engineering, Army Engineering University of PLA, Nanjing 210007, China School of Civil Engineering, Southeast University, Nanjing 210096, China, E-mail: 83812546@qq.com, Tel: 86-025-80821029
}

tures [7-9], off-shore and marine structures. With respect to delicate lightweight structures, such as aviation structures [10-12], telescope [13], and satellites [14], CFRP profiles are often used as component in those truss type structures. Although the working conditions of CFRP components in those truss structures only include axial loading, typical design methodologies require off-axis piles to assist in off-axis loading and damage tolerance [11]. In fact CFRP laminated tubes with off-axis ply orientations also show better mechanical properties in strength [15], dynamic performance [16], and imperfection resistance [17, 18]. Given that the laminated CFRP tubes mainly bears axial compression, we put forward a typical stacking sequence $\left[0^{\circ}{ }_{4} / \pm \theta\right.$ ] which exhibits four unidirectional plies to achieve high bending rigidity and two off-axis plies to provide lateral support for unidirectional plies. Our previous studies [15] mainly focused on the behaviour of short CFRP laminated tubes under axial compression (which was dominated by strength failure). The study demonstrates that off-axis pile angle $\theta$ significantly influences the average strength of the laminated CFRP tube. Specimens with $\pm 60^{\circ}$ surface plies appear to provide the best axial compression behaviour which is $21.6 \%$ higher than that of tubes with all unidirectional piles.

For laminated CFRP tubes in practical truss structures, longer components will be more used which will be dominated by overall buckling failure. Hence, for future practical application of this CFRP laminated tube, it is necessary to study their overall buckling behaviour. Recent studies on FRP compression profiles mainly focus on the profiles of pultruded glass-fibre reinforced plastics (GFRP) with different cross sections shapes such as channel sections [19], 'Universal' and 'Box' [20], 'I-shaped' [21], and circular cross sections [22, 23]. These studies indicate that the Euler formula is accurate for components with high slenderness ratio $\lambda$. With respect to components with small $\lambda$, the Euler buckling load significantly exceeds the test results, and thus, the Euler formula is unsafe for design. Zureick [24] found that when the ratio of longitudinal elastic modulus $E_{L}$ to transverse shear modulus $G_{L T}$ is high (i.e., more than 6), it is necessary to consider the effects of transverse shear. Because of the high $E_{L} / G_{L T}$ ratio 
that FRP material generally display, Zureick proposed that a reduction factor of 0.85 should be added to the original Euler formula. With respect to obtaining the practical column curves for design, the Perry-Robertson formula [25] was often adopted to fit the experiment data. The obtained column curve accurately predicts the overall buckling critical load of pultruded GFRP long tubes. However, there are currently a very limited number of studies $[11,26]$ on the overall buckling behaviour of long CFRP tubes with offaxis ply orientation, not to mention their practical column curves for design.

The present study focuses on the overall buckling behaviour and design of long CFRP laminated tubes with various off-axis ply orientations. 60 long tubes are prepared and designed with a stacking sequence $\left[0^{\circ}{ }_{4} / \pm \theta\right.$, with $\theta$ corresponding to either $0^{\circ}, 90^{\circ}, 45^{\circ}$ or $60^{\circ}$. All long CFRP tubes are tested under axial compression with effective end-reinforcement to simulate hinge support. Based on the test data, column curves for CFRP long tubes are obtained using the traditional Perry-Robertson stability formula. Finally, we compare the test results and the predicted value, and therefore propose a strategy for safe design and obtain a reduction factor based on statistical analysis. Furthermore, the experiment and associated analysis contribute to supplementing the benchmark data library of overall bucking behaviour of relatively long CFRP tube, and this obtained column curve can serve as calibration datum for future study or as separate reference for CFRP tube design.

\section{Specimens and test setup}

\subsection{Specimens}

All specimens were fabricated from carbon/epoxy preimpregnated tapes made of T700 carbon fibres in YPH-307 epoxy resin, provided by Toray Industries, Inc. The main manufacturing process is shown in Fig. 1, which includes four main procedures: (1) cutting pre-impregnated tapes; (2) rolling the pre-impregnated tapes on the steel mandrel through a coiling machine; (3) curing the specimens in temperature-box for $2 \mathrm{~h}$ at $130^{\circ} \mathrm{C}$; (4) demoulding and obtain the final specimens. The elastic constants of the T700SC/YPH-307 unidirectional laminates are provided by the manufacturer, as presented in Table 1. All CFRP tubes have the same cross section with a thickness of $0.9 \mathrm{~mm}$ and an inner diameter of $18 \mathrm{~mm}$. The CRFP tube length $L$ varies from $250 \mathrm{~mm}$ to $800 \mathrm{~mm}$. A schematic of the test specimens is shown in Fig. 2. Due to the high stiffness values,
CFRPs can hardly reduce stress concentration by deformation [27]. In order to avoid stress concentrations near the end closures and end failure, a special method was used to avoid local failures during tests namely constructions with an E-glass fibre/epoxy resin material in filament wounds. The plugs were used as end closures inside the tube end corners.
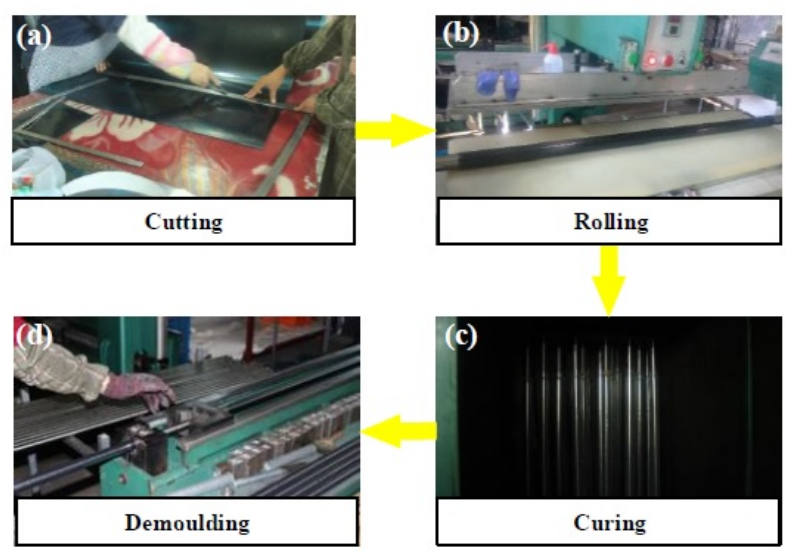

Figure 1: Manufacturing process of laminated CFRP tubes

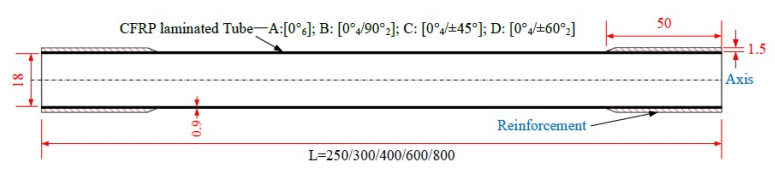

Figure 2: Schematic of the specimens (dimensions unit: $\mathrm{mm}$ )

Based on Hashem's conclusion [20], overall buckling behaviour of FRP columns will occur at slenderness ratio $\lambda \geq 50$. Long tubes of $L=250,300,400,600$, and $800 \mathrm{~mm}$ were designed with four types of stacking sequences $\left[0^{\circ}{ }_{6}\right]$, $\left[0^{\circ}{ }_{4} / 90^{\circ}{ }_{2}\right],\left[0^{\circ}{ }_{4} / \pm 45^{\circ}\right]$, and $\left[0^{\circ}{ }_{4} / \pm 60^{\circ}\right]$ denoted as $\mathrm{A}, \mathrm{B}$, $\mathrm{C}$, and $\mathrm{D}$ respectively. Three specimens were designed for each length and each ply orientation, and the total number of long CFRP tube specimens was 60 . The specimens are denoted as L-length-lamination-number. The detailed information of the 60 specimens are summarized in Table 2. For these long tubes, the effective specimen length $L_{0}$ corresponds to the distance between the centres of the two hinge supports. Hence, $L_{0}$ can be calculated as $L+100 \mathrm{~mm}$, where $L$ is the length of the specimen, $100 \mathrm{~mm}$ is twice the distance between the end of the specimen and the pin centre. The influence of metal supports on the bearing capacity can be neglected [28]. Thus, the $\lambda$ for tubes of six different lengths can be calculated as $\lambda=52,60,75,105$, and 135 . 
Table 1: Elastic constant of the T700 / YPH-307 systems

\begin{tabular}{ccc}
\hline Strength $(\mathrm{MPa})$ & Modulus of elasticity $(\mathrm{GPa})$ & Poisson's ratio \\
\hline $0^{\circ}$ compress $=835$ & & \\
$0^{\circ}$ tensile $=1580$ & $\mathrm{E}_{1}=95$ & $v_{12}=0.3$ \\
$90^{\circ}$ compress $=103$ & $\mathrm{E}_{2}=7.4$ & \\
$90^{\circ}$ tensile $=31$ & $\mathrm{G}_{12}=3.6$ & \\
In-plane shear $=53$ & & \\
\hline
\end{tabular}

Table 2: Dimensions of the specimens

\begin{tabular}{ccccc}
\hline Specimen & $D \times t(\mathrm{~mm})$ & $L(\mathrm{~mm})$ & $L_{0}(\mathrm{~mm})$ & $\lambda$ \\
\hline L-250-A/B/C/D-1/2/3 & $19.8 \times 0.9$ & 250 & 350 & 52 \\
L-300-A/B/C/D-1/2/3 & $19.8 \times 0.9$ & 300 & 400 & 60 \\
L-400-A/B/C/D-1/2/3 & $19.8 \times 0.9$ & 400 & 500 & 75 \\
L-600-A/B/C/D-1/2/3 & $19.8 \times 0.9$ & 600 & 700 & 105 \\
L-800-A/B/C/D-1/2/3 & $19.8 \times 0.9$ & 800 & 900 & 135 \\
\hline
\end{tabular}

\subsection{Test setup}

The simply supported boundary condition is desired for the long tube compression test. To simulate this boundary condition, a special fixture consisting of pins, bearings, male lugs, and female jaws (in Fig. 3(a)) was designed and installed on both ends of the specimens. The ends of the tubes were filled with small steel circular cylinders on a male lug. The fixture connected to the top-end of the specimens was attached to a $50-\mathrm{kN}$ load cell, which was in turn tied to the reaction frame. Meanwhile, the fixture connected to the bottom-end of the specimens was attached to the ground. For male lug can only rotate in the plane determined by female jaw, the corresponding mounted CFRP tubes will rotate in the same plane. To keep the specimens vertical, a plumb line from the upper to the lower female jaw was used for calibration propose.

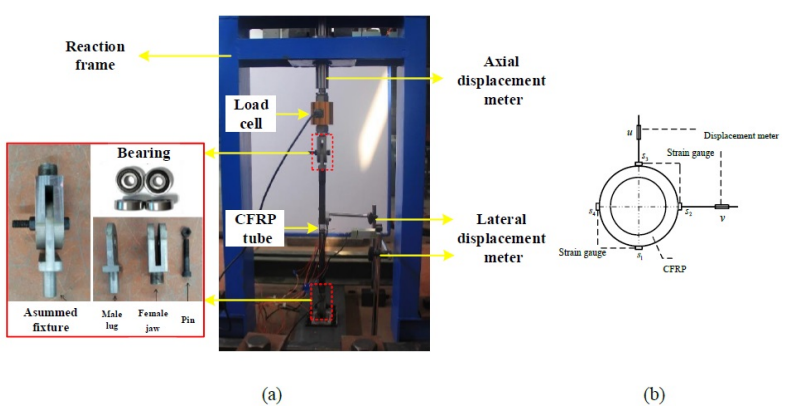

Figure 3: Long tube compression test (a) set-up details, (b) strain gauge and displacement meter configuration
Three electronic displacement meters (KTM-A2$50 \mathrm{~mm}$ ) were used to obtain load-displacement properties. One was installed at the top of the load cell to measure the axial displacement, and the other two were installed at the mid-height of each specimen to record the lateral displacements marked as $u$ and $v$, representing lateral displacement in the rotating plane and out of the rotating plane respectively (in Fig. 3(a)). To obtain the axial strain and buckling of the CFRP tubes at each load step, a total of four axial electrical strain gauges $(120.2 \pm 0.1 \Omega$ ) (named $S_{1} \sim S_{4}$ ) were attached to the outer surface of the mid span of each specimen (in Fig. 3(b)). $S_{1}$ and $S_{3}$ were in plane and $S_{2}$ and $S_{4}$ were out of plane. To control eccentric load, the position of CFRP specimens were also adjusted by comparing the measurements of four strain gauges across the mid-section after applying a small load.

\section{Test results}

The test specimens were compressed until failure or load limit was reached. Totally four types of failure modes were observed for the 60 specimens during loading. Penetrative split was observed for specimens L-250-A-1, L-250A-2, L-250-A-3, L-300-A-2, and L-300-A-3. Due to the relatively small slenderness ratio of these tubes, the stress level of these tubes is much higher than that of longer tubes when approaching ultimate compressive load. The result demonstrated that without off-axis piles, matrix failure in transverse tension is easy to happen in these $\left[0_{6}\right]$ tubes. Strength failure occurs in these above specimens, so the corresponding result is invalid. $\mathrm{L}-250-\mathrm{C}-1$ was crushed 
abruptly near the end rendering the data invalid. The top hinged support for L-300-D-2 and L-300-D-3 did not rotate during loading, leaving the bearing condition uncertain, and hence, these specimens were also invalid. With totally 8 invalid specimens, the remaining 52 valid specimens were characterized with typical overall buckling failure.
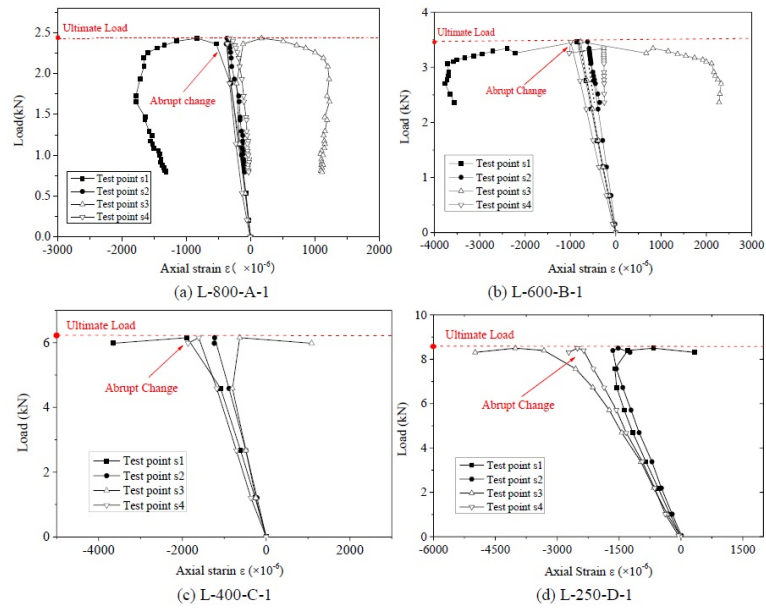

Figure 4: Load-strain curves for tubes of different lengths

The valid data from 52 specimens constitutes a remarkably large volume. Since load-stain relationships of these long tubes are similar, only test curves of L-800-A-1, L-600B-1, L-400-C-1, and L-250-D-1 are presented in Fig. 4 without loss of generality. These four tubes cover four stacking sequences and four lengths. The strains of four test points $S_{1}-S_{4}$ were recorded. $S_{1}$ and $S_{3}$ were in the rotating plane mentioned above and these points were used to determine the critical load with strain change. $\mathrm{S}_{2}$ and $\mathrm{S}_{4}$ were out of the rotating plane and were mainly used for checking and adjusting the specimen position during early stages of loading. According to Fig. 4, during early stages of loading, the load-strain curves of these 52 valid specimens show a good linear elastic characteristic. When the strain of $S_{1}$ and $S_{3}$ reaching limit point, the bending deformation abruptly increased leading to significant change of strain $S_{1}$ and $S_{3}$. The development of strains for $S_{1}$ and $S_{3}$ was random and highly related to the initial bending direction. After the limit point was reached, additional bending moment became the primary stress type instead of compressive force. This change of strain markedly showed that the tube lost stability. Among all the obtained curves, the variation of strains of $S_{1}$ and $S_{3}$ was much greater than strains of $S_{2}$ and $S_{4}$ after overall buckling, indicating that over- all buckling occurs in-plane and the steel hinge supports worked well.

The load-lateral displacement curves for these four tubes are presented in Fig. 5. $u$ and $v$ are the lateral displacement in-plane and out-of-plane, respectively. The load-lateral displacement curves show similar characteristic with the corresponding load-strain curves. Before ultimate load was reached, the lateral displacement slowly increased. After reaching the critical load, lateral displacements significantly increase. The development of overall buckling for tubes with different lengths is also included as photographs in Fig. 5(a)-(d). The left photograph is an unloaded tube, the photograph on the right is a tube after reaching ultimate load, while that in the middle is a tube undergoing loading. As seen from the curves, the lateral deformation of the specimens is almost in the shape of a half-wave sine curve which is typical characteristic of overall bucking. It can be concluded that all specimens show similar load-displacement behaviours. Firstly, at initial loading, the lateral displacement in-plane increases gradually. The deformation is mainly contributed to axial compression. When reaching ultimate load, a brief cracking sound was heard indicating failure of the laminated tubes. After specimen failure, the axial stiffness and equivalent bending stiffness of the tube greatly decreased. The lateral displacements $u$ and $v$ significantly increased which are contributed by the combined effect of axial load and additional large bending moment and the significantly reduced stiffness.
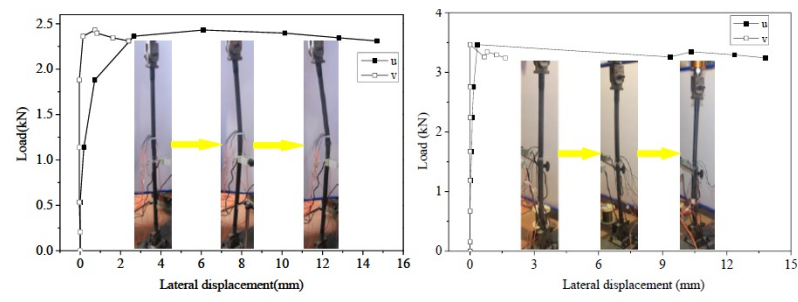

(a) L-800-A-1
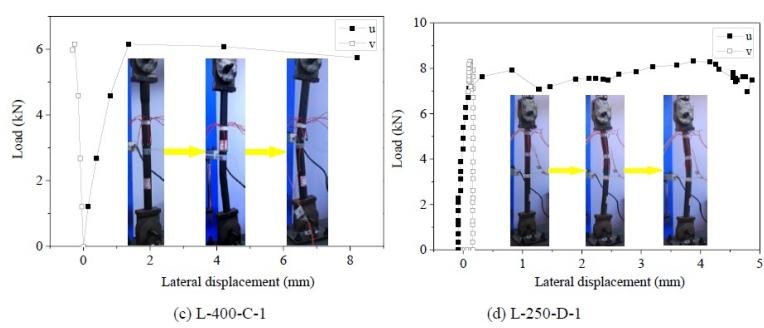

Figure 5: Load-lateral displacement curves for tubes with different lengths

The load-axial displacement curves for the above four tubes are presented in Fig. 6. Two segments can be di- 


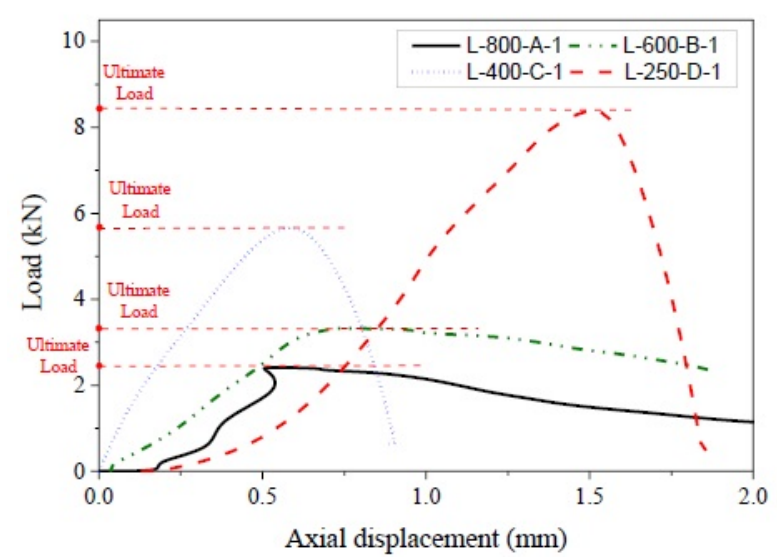

Figure 6: Load-axial displacement curves for tubes with different lengths

vided, namely linear growth segment and nonlinear decrease segment. The limit point is also an indicator of overall buckling critical load. In summary, all the loaddisplacement curves of these CFRP tubes show upward section, downward section, and the limit point. Hence, the buckling type of these CFRP tubes is typically limitpoint instability. According to classical Euler formula 11.04.2019, the two most influential factors of the overall buckling load are equivalent bending stiffness EI and tube length L. According to our previous research [29], the order of equivalent bending stiffness EI for stacking sequences $\mathrm{A}, \mathrm{B}, \mathrm{C}$ and $\mathrm{D}$ are as follows: $\left[\mathrm{O}_{6}\right]>\left[\mathrm{0}_{4} / \pm 45\right]>$ $\left[\mathrm{O}_{4} / \pm 60\right]>\left[\mathrm{O}_{4} / 9 \mathrm{O}_{2}\right]$, and the equivalent bending stiffness of $\left[0_{6}\right]$ is about $38.8 \%$ higher than that of $\left[0_{4} / 90_{2}\right]$. The order of average ultimate loads for the four types of tubes are as follow: L-250-D $(10988 \mathrm{~N})>\mathrm{L}-400-\mathrm{C}(6109 \mathrm{~N})>\mathrm{L}-600-\mathrm{B}$ $(3540 \mathrm{~N})>$ L-800-A $(2918 \mathrm{~N})$. Although the equivalent bending stiffness of $B$ is much smaller than that of $A$, the average ultimate load of tube L-600-B is still $21.3 \%$ higher than that of L-800-A. The equivalent bending stiffness of $\mathrm{C}$ and $\mathrm{D}$ is similar, and the average ultimate load of tube L-250$\mathrm{D}$ is $79.9 \%$ higher than that of L-400-C. All these demonstrate that tube length is the most influential factor of ultimate buckling load. The ultimate loads for all the 52 valid specimens (listed in the appendix) also reflect this conclusion. Other influential factors of test ultimate loads include manufacturing defects (ply angles can hardly be precisely controlled due to handmade technic), imperfection sensitivity of different stacking sequences, inherent discreteness characteristic of FRP material, different initial out-ofstraightness, and test measure error etc. Hence, the test results show some variation. In order to accurately predict overall buckling load of CFRP laminated tubes, it is necessary to take all these influential factors into account from a statistical perspective, namely to obtain the column curves of laminated CFRP tubes.

\section{Column curves}

Slenderness ratio $\lambda$ is an important factor for indicating the overall bucking critical load of struts, which can be calculated as ratio of the calculated length and radius of gyration. Given that the material properties of FRP components (such as strength and elastic modulus) are greatly influenced by stacking sequence, universal slenderness ratio $\bar{\lambda}$ is selected for generalisation propose that is calculated by equation (1)

$$
\bar{\lambda}=\frac{\lambda}{\pi} \sqrt{f_{y} / E}
$$

where, $f_{y}$ denotes the ultimate strength obtained from short tube compression tests [15].

With respect to classical Euler equation, the critical load of overall buckling can be calculated as $P_{c r}=\pi^{2} E I /$ $l_{0}{ }^{2}$. Thus, the reduction factor of Euler buckling $\phi_{\text {Euler }}$ can be obtained from equation (2). The experimental reduction factor can be calculated as $\phi_{\text {test }}=P_{u} / f_{y} \mathrm{~A}_{c}$, where $\mathrm{A}_{c}$ denotes the cross-sectional area and $P_{u}$ denotes the experimental ultimate bearing load of the tube.

$$
\phi_{\text {Euler }}=\frac{1}{\bar{\lambda}^{2}}
$$

The Perry-Robertson formula [25] (P-R formula) is a mathematical formula to produce a good approximation of flexural buckling load. This formula is regarded as the basis of many design codes for steel struts and is often used as an accurate approach to fit column curve of FRP struts [23, 30,31]. The corresponding reduction factor $\varphi$ can be written as:

$$
\varphi=\left(1 / 2 \bar{\lambda}^{2}\right)\left[\left(1+\varepsilon_{0}+\bar{\lambda}^{2}-\sqrt{1+\varepsilon_{0}+\bar{\lambda}^{2} 2-4 \bar{\lambda}^{2}}\right]\right.
$$

where $\epsilon_{0}$ denotes relative initial bending defined as $\varepsilon_{0}=$ $\left(\mathrm{A} v_{0}\right) / W$ ( $W$ denotes section modulus). When the formula is used to fit column curves, actually the relative initial bending $\epsilon_{0}$ not only relates to initial bending but also includes other initial imperfections such as material defects and loading eccentricity [32].

According to GB50018-2002 [33], the relative initial bending can be assumed to take the following form:

$$
\varepsilon_{0}=a+b \bar{\lambda}^{2}
$$

The fitted curve and formula of the initial relative bending for three types stacking sequences are shown in Fig. 7-9(a), in which the least square method was adopted. 


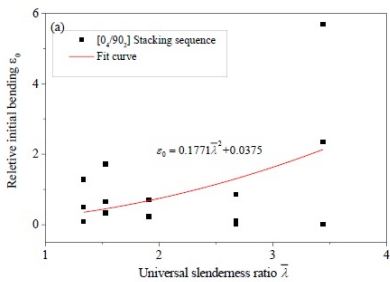

(a)

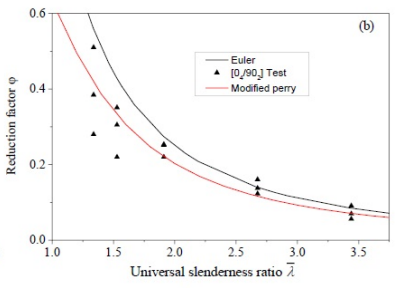

(b)
Figure 7: Stacking sequence $\left[0_{4} / 90_{2}\right]$ (a) initial relative bending fitting and (b) modified Perry fitting curves

The initial relative bending $\epsilon_{0}$ is deduced through equation (3) based on experimental reduction factor. Given that five tests for stacking sequence A $\left(\left[\mathrm{O}_{6}\right]\right)$ are invalid, the fitting wasn't conducted for stacking sequence A. The fitted formulas of the three stacking sequences were brought into equation (3) and the P-R formula stability factor fitting curves are plotted in Fig. 7-9(b). It can be concluded that when is high, the P-R formula curve is close to the Euler curve; when is small, the gap between the two curves is large and the P-R formula curve is clearly more accurate and safer.

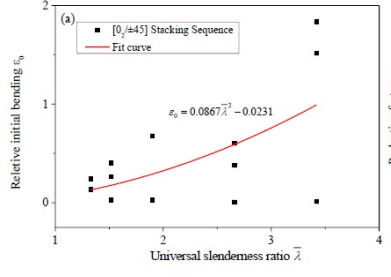

(a)

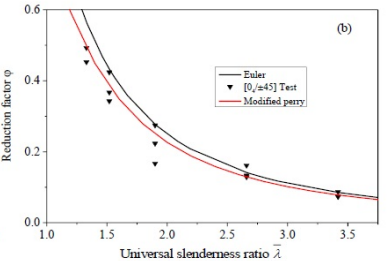

(b)
Figure 8: Stacking sequence $\left[0_{4} / \pm 45\right]$ (a) initial relative bending fitting and (b) modified Perry fitting curves

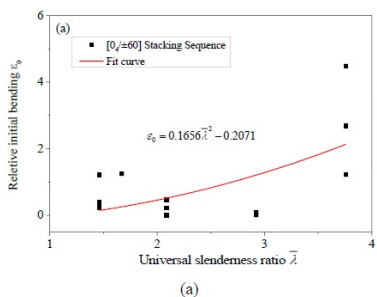

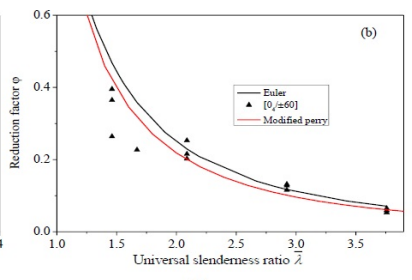

(b)
Figure 9: Stacking sequence $\left[0_{4} / 60_{2}\right]$ (a) initial relative bending fitting and (b) modified Perry fitting curves

Although not included in the test database, the test result of five $\left[\mathrm{O}_{6}\right.$ ] tubes (namely L-250-A-1, L-250-A-2, L-250A-3, L-300-A-2, and L-300-A-3) demonstrated that matrix transverse tension failure is easy to happen in these rel- atively short $\left[\mathrm{0}_{6}\right]$ tubes without off-axis piles. It can be explained that without the outer oblique wrapping ply, the development of initial defect which inevitably exists during manufacturing process [14] can hardly be constrained. The premature failure lowers the ultimate load of these tubes, indicating $\left[\mathrm{O}_{6}\right]$ is not the best stacking sequence for laminated CFRP tube, especially for short tubes. The stacking sequence $\left(\left[0^{\circ}{ }_{4} / 90^{\circ}{ }_{2}\right]\right)$ has the smallest equivalent longitudinal elastic modulus, which leads to lower ultimate load. For $\left[0^{\circ}{ }_{4} / \pm 45^{\circ}\right]$ and $\left[0^{\circ}{ }_{4} / \pm 60^{\circ}\right]$ tubes, the matrix transverse tension failure can be prevented to some extent, and meanwhile their equivalent bending stiffnesses do not reduce too much. Although test data quantity for CFRP tubes of each stacking sequence is not large enough and the fitted result may be affected by a few special points to a certain degree, these fitted curves also demonstrate that the CFRP tubes with oblique off-axis ply orientation (mainly $\left[0^{\circ}{ }_{4} / \pm 45^{\circ}\right]$ and $\left[0^{\circ}{ }_{4} / \pm 60^{\circ}\right]$ ) have better overall bucking performance. The data of the four stacking sequences (totally 52 effective test points) was also fitted, and the P-R formula fitting curve was plotted as red solid line in Fig. 10. The all-data fitted curve is close to the lower bound of the three column curves for stacking sequences B, C and D. For practical engineering applications, it is safe to adopt this curve as the column curve for stability design.

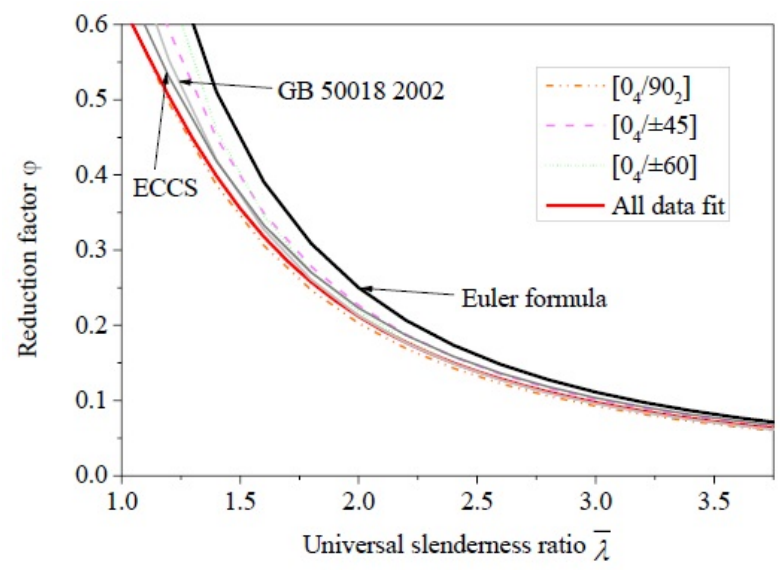

Figure 10: Comparison of the modified Perry fitting curves for three stacking sequences.

In the Chinese Technical code of cold-formed thinwall steel structures (GB50018-2002) [33], $\epsilon_{0}$ was obtained using equation (5).

$$
\varepsilon_{0}=0.05+0.15 \bar{\lambda}^{2}(\bar{\lambda}>1.0)
$$

In the European Convention of Constructional Steelwork (ECCS) [34], $\epsilon_{0}$ was obtained by using equation (6). 


$$
\varepsilon_{0}=0.21(\bar{\lambda}-0.2)(\bar{\lambda}>0.2)
$$

The corresponding two column curves are also plotted in Fig. 10 as light grey curves. It is shown in the figure that the column curves of steel technical code are below the curves of stacking sequence $\mathrm{C}$ and $\mathrm{D}$ but higher than stacking sequence $B$ and the all data fitted curves. The difference is obviously bigger when universal slenderness ratio $\bar{\lambda}$ is small. It can be explained that when $\bar{\lambda}$ is small, the component bears a higher stress level, which will more likely lead to expansion of defects that is greatly affected by stacking sequences. Additionally, the transverse shear effect is significant when universal slenderness ratio is small, which greatly affects the ultimate load of CFRP laminated tube. The large difference of those column curves indicates that direct adoption of steel technical codes for CFRP tubes with off-axis ply orientation is inappropriate. However, it can be concluded that when universal slenderness ratio is relatively large, all the column curves including those of ECCS, GB50018-2002, and even Euler formula are close to each other. Thus, in preliminary design of CFRP laminated tube with large slenderness ratio, all these column curves can be adopted.

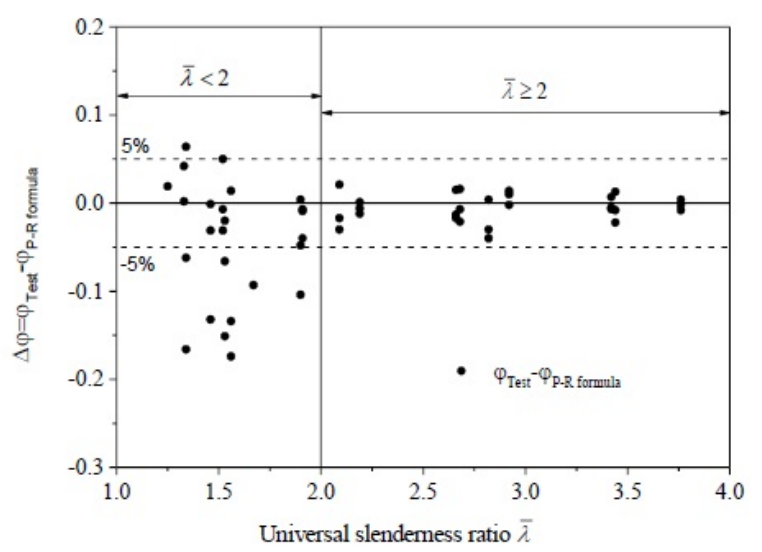

Figure 11: Error distribution of theoretical and experimental stability factors of CFRP tubes

In Fig. 11, the difference of the P-R formula fitting curve results and test results for 52 points was shown, where the horizontal axis is $\bar{\lambda}$ and the longitudinal axis is the difference. Obviously, when universal slenderness ratio $\bar{\lambda}>2$, the difference of critical buckling loads is quite small (all within $5 \%-5 \%$ ); when universal slenderness ratio $\bar{\lambda}<2$, the range of the difference is wide (the largest difference can reach 20\%). This can be attributed to the unavoidable inherent discreteness of the FRP material (as can be seen form the distribution of test points in Fig. 12). Thus, with respect to unpredictability of the discreteness, it is necessary to propose a strategy of column curve for safe design.

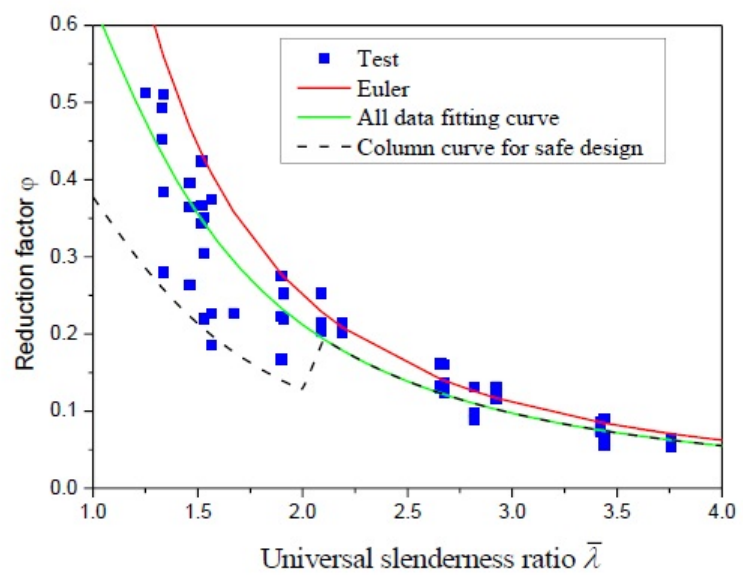

Figure 12: Comparison of stability factor curves for CFRP tubes

When $\bar{\lambda}<2$, a factor $\Phi$ should be added to ensure safe design. It can be assumed [35] that quotient $\eta=\varphi_{\text {P-Rformula }} / \varphi_{\text {Test }} \sim \mathrm{N}\left(\mu, \sigma^{2}\right)$, where $\mathrm{N}\left(\mu, \sigma^{2}\right)$ denotes normal distribution, $\mu$ denotes the average value, and $\sigma^{2}$ denotes the variance. The test points are used as the statistical sample. The statistical analysis of $\eta$ for CFRP was conducted, as shown in Table 3. If failure probability is $5 \%$, the safe factor $\Phi$ can be calculated as $\Phi=1 /(\mu+1.6 \sigma)$. Then, $\Phi_{C F R P}=0.6$. Black dash line in Fig.12 is the ultimate column curve for safe design.

The fitted column curve strongly relies on test results; therefore, it may be not accurate enough due to limited amount of test data. However, the proposed strategy of column curve for design can be applied by other researchers as reference. More studies should be made on other stacking sequence except $\left[0^{\circ}{ }_{4} / \pm \theta^{\circ}\right]$, which will be detailed in subsequent studies.

\section{Conclusions}

In this study, 60 CFRP tubes with off-axis ply orientations were tested under concentric compression loads. The overall buckling behaviour was examined and column curves were fitted based on the Perry-Robertson formula. A strategy for safe design was proposed based on the statistical analysis. The following conclusions were obtained:

1. The proposed method for the axial compression tests on CFRP tubes was effective in simulating simple- 
Table 3: Statistical analysis of $\eta$ for CFRP

\begin{tabular}{cccccc}
\hline Type & $\max$ & $\min$ & Average $\mu$ & Standard deviation $\sigma$ & Scatter $\sigma / \mu$ \\
\hline CFRP & 1.69 & 0.87 & 1.20 & 0.29 & $24.2 \%$ \\
\hline
\end{tabular}

supported boundary condition and providing a basis to examine the overall bucking behaviour of CFRP tubes.

2. Both the load-strain and load-displacement curves can be divided into two segments during loading process, namely the linear elastic segment and nonlinear post-bucking segment. The transformation of the two segments underwent abrupt changes that denote the overall bucking. With respect to the CFRP tubes under compression, the lateral deformation of specimens is nearly half-wave sine curve shape when overall bucking was achieved. The CFRP tubes exhibited typical limit-point instability buckling, and these tubes underwent brittle failure after reaching the critical load.

3. The Euler curve is unsafe for designing CFRP tubes with off-axis ply orientation. The column curves of steel technical codes GB50018-2002 and ECCS are inappropriate in view of the that CFRP tubes with different stacking sequences generate different column curves. The column curve based on all 52 valid test data is almost the lower boundary of all the column curves.

4. Given the inevitable large discreteness of FRP material, a reduction factor $\Phi$ should be added to the previously obtained columns curve for safe design especially when universal slenderness ratio $\bar{\lambda}<2$. Based on statistical analysis, $\Phi_{C F R P}=0.6$, when failure probability is $5 \%$.

Acknowledgements: The authors wish to acknowledge their team members for their assistance in conducting the experiments. Thanks are also given to reviewers for their insightful comments and helpful suggestions on the quality improvement of our present paper.

Declaration of conflicting interests: The author(s) declare no potential conflicts of interest with respect to this work and the authorship and/or publication of this article.

Funding: Supports from the National Key Research and Development Program of China (Award No. 2017YFC0703008), the National Natural Science Foundation of China (Award Nos. 51778620 and 51708552), the National Natural Science Foundations of Jiangsu Province (Award No. BK20170752), the Young Elite Scientist Spon- sorship (17-JCJQ-QT-020) and China Postdoctoral Science Foundation (Award No.2017M611657) are gratefully acknowledged.

\section{References}

[1] Hollaway LC. Constr. Build. Mater. 2010, 24, 2419-45.

[2] Hollaway LC. Constr. Build. Mater. 2003, 17, 365-78.

[3] Zhang D, Zhao Q, Li F, Li F. Ksce. J. Civ. Eng. 2016, 20, 2447-56.

[4] Zhang D, Zhao Q, Huang Y, Li F, Chen H, Miao D. Compos Struct.2014, 108, 600-15.

[5] Kostopoulos V, Markopoulos YP, Vlachos DE, Katerelos D, Galiotis C, Tsiknias T. Plast Rubber Compos. 2013, 34, 201-207.

[6] Pfeil MS, Teixeira AMAJ, Battista RC. Compos Struct. 2009, 89, 70-76.

[7] Yang X, Bai Y, Ding F. Compos Struct. 2015, 133, 986-996.

[8] Bai Y, Zhang C. Compos Struct. 2012, 94, 47-53.

[9] Hagio H, Utsumi Y, Kimura K, Takahashi K, Itohiya G. Advanced Materials for Construction of Bridges, Buildings, and Other Structures III, ECI Digital Archives, 2003

[10] Soutis C. Prog Aerosp Sc. 2005, 41, 143-151.

[11] Jegley DC, Wu KC, Phelps JE, Mckenney MJ, Oremon L. J Spacecraft Rockets. 2012, 49, 915-924.

[12] Brewster JW. NASA/CR-2009-215957,2009

[13] Jessen NC, Nørgaard-Nielsen HU, Schroll J. Compos Struct. 2008, 82, 310-316.

[14] Takagaki K, Minakuchi S, Takeda N. Compos Struct. 2015, 126, 337-446.

[15] Tao J, Li F, Zhao Q, Zhang D. J. Reinf. Plast. Compos. 2016, 36, $1-15$.

[16] Will MA, Franz T, Nurick GN. Compos Struct. 2002, 58, 259-270.

[17] Kassegne SK, Chun K. I J Struct E. 2015, 7, 1-10.

[18] Caminero MA, Rodríguez GP, Muñoz V. Compos Struct. 2016, 2016, 345-357.

[19] Hewson P. Composites. 1978, 9, 56-60.

[20] Hashem ZA, Yuan RL. Constr Build Mater. 2001, 15, 369-378.

[21] Barbero EJ, Trovillion J. Compos Sci Technol. 1998, 58, 13351341.

[22] P Qian. Research on FRP and FRP-Aluminum Alloy Composite Pipes under Axial Force [Doctoral thesis]: Tsinghua University:beijing, 2006.

[23] Puente I, Insausti A, Azkune M. J Compos Conster. 2006, 10, 529 537.

[24] Zureick AH, Scott DW. J Compos Conster. 1997, 1, 140-149.

[25] Ayrton W, Perry J. On struts. The Engineer: London,1866.

[26] Bo N, Yue W, Hao-tian S. Engineering Mechanics. 2017, 34, $92-$ 100. (in chinese)

[27] Schultheisz CR, Waas AM. Prog Aerosp Sci. 1996, 32, 31-42.

[28] Nong GX. Theoretical and experimental research on the Aluminum alloy structures members [Doctoral thesis]: Tongji Uni- 
versity: shanghai, 2006.

[29] Henming Z, Feng L, Darong P. Acta Matriae Compositae Sinica. 2016, 33, 1694-1701.

[30] Zhan Y, Wu G, Harries KA. Eng Struct. 2018, 158, 1-12.

[31] Feng P, Hu L, Qian P, Ye L. Eng Struct. 2017, 132, 624-36.

[32] Ji C. The international conference on quality and reliability in welding. Hangzhou ,1984, Vol.3, p 6.

[33] China MOCO. Technical code of cold-formed thin-wall steel structures GB 50018-2002. China Planning Press: Beijing, 2002. (in chinese)

[34] Stinteso DE. European Convention of Constructional Steelworks Manual on the Stability of Steel Bulidings. $2^{\text {nd }}$ ed., ECCS: Paris, 1976, 55-97.

[35] Qian P, Feng P, Ye L. J Tianjin Uni. 2007, 40, 19-23. 


\section{Appendix}

Summary of the ultimate loads for all the 52 valid specimens:

\begin{tabular}{lccc|cccc}
\hline Specimen & $\begin{array}{c}\text { Universal } \\
\text { slenderness } \\
\text { ratio }\end{array}$ & $\begin{array}{c}\text { Ultimate } \\
\text { Load }\end{array}$ & $\varphi_{\text {test }}$ & Specimen & $\begin{array}{c}\text { Universal } \\
\text { slender- } \\
\text { ness } \\
\text { ratio }\end{array}$ & $\begin{array}{c}\text { Ultimate } \\
\text { Load }\end{array}$ & $\varphi_{\text {test }}$ \\
\hline L-250-B-1 & 1.34 & 9707 & 0.384 & L-400-D-2 & 2.09 & 6517 & 0.202 \\
L-250-B-2 & 1.34 & 7069 & 0.280 & L-400-D-3 & 2.09 & 6931 & 0.215 \\
L-250-B-3 & 1.34 & 12879 & 0.510 & L-600-A-1 & 2.19 & 5552 & 0.202 \\
L-250-C-2 & 1.33 & 13586 & 0.493 & L-600-A-2 & 2.19 & 5707 & 0.208 \\
L-250-C-3 & 1.33 & 12483 & 0.453 & L-600-A-3 & 2.19 & 5914 & 0.215 \\
L-250-D-1 & 1.46 & 8500 & 0.264 & L-600-B-1 & 2.68 & 3466 & 0.137 \\
L-250-D-2 & 1.46 & 12724 & 0.395 & L-600-B-2 & 2.68 & 4052 & 0.160 \\
L-250-D-3 & 1.46 & 11741 & 0.365 & L-600-B-3 & 2.68 & 3104 & 0.123 \\
L-300-A-1 & 1.25 & 14069 & 0.512 & L-600-C-1 & 2.66 & 3672 & 0.133 \\
L-300-B-1 & 1.53 & 8862 & 0.351 & L-600-C-2 & 2.66 & 3552 & 0.129 \\
L-300-B-2 & 1.53 & 7707 & 0.305 & L-600-C-3 & 2.66 & 4448 & 0.161 \\
L-300-B-3 & 1.53 & 5552 & 0.220 & L-600-D-1 & 2.92 & 4241 & 0.132 \\
L-300-C-1 & 1.52 & 11690 & 0.424 & L-600-D-2 & 2.92 & 3724 & 0.116 \\
L-300-C-2 & 1.52 & 9448 & 0.343 & L-600-D-3 & 2.92 & 4121 & 0.128 \\
L-300-C-3 & 1.52 & 10121 & 0.367 & L-800-A-1 & 2.82 & 2431 & 0.088 \\
L-300-D-1 & 1.67 & 7310 & 0.227 & L-800-A-2 & 2.82 & 2707 & 0.098 \\
L-400-A-1 & 1.56 & 10293 & 0.374 & L-800-A-3 & 2.82 & 3621 & 0.132 \\
L-400-A-2 & 1.56 & 6224 & 0.226 & L-800-B-1 & 3.44 & 2293 & 0.091 \\
L-400-A-3 & 1.56 & 5104 & 0.186 & L-800-B-2 & 3.44 & 1414 & 0.056 \\
L-400-B-1 & 1.91 & 5552 & 0.220 & L-800-B-3 & 3.44 & 1759 & 0.070 \\
L-400-B-2 & 1.91 & 6345 & 0.251 & L-800-C-1 & 3.42 & 2397 & 0.087 \\
L-400-B-3 & 1.91 & 6396 & 0.253 & L-800-C-2 & 3.42 & 2069 & 0.075 \\
L-400-C-1 & 1.90 & 6155 & 0.223 & L-800-C-3 & 3.42 & 2017 & 0.073 \\
L-400-C-2 & 1.90 & 4603 & 0.167 & L-800-D-1 & 3.76 & 2086 & 0.065 \\
L-400-C-3 & 1.90 & 7569 & 0.275 & L-800-D-2 & 3.76 & 1897 & 0.059 \\
L-400-D-1 & 2.09 & 8138 & 0.253 & L-800-D-3 & 3.76 & 1707 & 0.053 \\
\hline & & & & & & &
\end{tabular}

where $\varphi_{\text {test }}$ is reduction factor of test result. 